\title{
A Defense of Preservation in the Age of MPLP
}

\author{
Jessica Phillips
}

\begin{abstract}
There has been much discussion of More Product, Less Process (MPLP) and its place within archives. However, few authors have examined MPLP's relationship to preservation. This article looks at Mark A. Greene and Dennis Meissner's attitudes toward preservation as revealed in their articles on MPLP, the relationship between access and preservation, and the importance of preservation within archives. It also offers strategies for efficient preservation.
\end{abstract}

(c) Jessica Phillips. (cc) BY-NC

\section{KEY WORDS}

Preservation, MPLP, More Product Less Process, Access, Processing 
This year marks the ten-year anniversary of the influential article "More 1 Product, Less Process: Revamping Traditional Archival Processing," in which Mark A. Greene and Dennis Meissner described what they see as the most significant problem plaguing the majority of archives: "Put very simply, processing is not keeping up with acquisitions and has not been for decades, resulting in massive backlogs of inaccessible collections at repositories across the country." 2 This is a significant problem, as large collection backlogs translate to materials that both are hidden and potentially contain agents of deterioration. The proposed solution for large, modern archives, More Product, Less Process (MPLP), suggests that archivists

need to articulate a new set of arrangement, preservation, and description guidelines that 1) expedites getting collection materials into the hands of users; 2) assures arrangement of materials adequate to user needs; 3) takes the minimal steps necessary to physically preserve collection materials; and 4) describes materials sufficient to promote use. In other words, it is time to focus on what we absolutely need to do, instead of on all the things that we might do in a world of unbounded resources. ${ }^{3}$

In a nutshell, MPLP created a framework for the processing of collections to the minimum level required for access and use. Greene and Meissner advocated performing all processing tasks at the same level within a collection or within a distinct portion of a collection. The result is that arrangement, description, and preservation must all occur at the same level (folder, series, box, etc.).

Over the course of five years, the authors expanded on their initial statement of MPLP with two additional articles. For the sake of clarity and brevity throughout this article, I will refer to Greene and Meissner as G\&M when discussing their initial article, "More Product, Less Process: Revamping Traditional Archival Processing," and as M\&G when discussing Meissner and Greene’s second article together, "More Application while Less Appreciation: The Adopters and Antagonists of MPLP." Not Just for Processing Anymore." ${ }^{5}$

"More Application while Less Appreciation" recognized laudatory articles while also addressing criticisms of MPLP. In it, the authors attempted to clarify an oft-misunderstood point and claimed that "More Product, Less Process" is about resource management, not specific processing actions, writing that the primary message is "not about processing desiderata like removing metal fasteners, arranging the physical items in a folder, or replacing file folders." 6 Unfortunately, this point did not come across clearly in the original work, where they spent much time deriding item-level tasks-particularly those pertaining to preservation. Still adhering to MPLP's insistence that the processing activities of arrangement, description, and preservation should all occur at an equal level and that it should usually be the one that requires the least amount 
of work to make the collection usable, M\&G noted that "levels should always be seen as upwardly negotiable, dependent only upon the sustainable resources at the repository's disposal."7 This is another point to which they alluded in the first article, ${ }^{8}$ yet their evident antipathy toward any foray into item-level work overshadows it.

In his perspective piece, "MPLP: It's Not Just for Processing Anymore," Greene summarized MPLP: "The goal is to work smarter, not harder; to do things 'well enough' rather than 'the best way possible' to accomplish more with less (or the same) resources." ${ }^{\circ}$ He attempted to demonstrate how MPLP can be applied to preservation, appraisal, and other archival functions. In discussing preservation, Greene reflected the opinions scattered throughout "More Product, Less Process" that archivists typically interpret minimal processing to mean not removing metal, replacing folders, photocopying clippings, or separating photos. ${ }^{10}$ In this, he also claimed that preservation most effectively “takes place at a level referred to as 'holdings maintenance' which means the efforts undertaken to maintain the totality of a repository's holdings, rather than efforts taken to preserve or conserve individual items or even small sets of items."11

This article is a response to the three articles by Greene and Meissner, with an examination of their attitudes toward preservation and use of inflammatory language; a brief review of the relevant literature surrounding MPLP and preservation; and a critical evaluation of the original survey conducted by Greene and Meissner. This article then continues with an examination of the role and significance of preservation in archives, archivists as trusted custodians of collections, preventive care strategies, and the importance of item-level preservation work. A definite need exists to eliminate backlogs in unprocessed archival collections; however, the strategies associated with MPLP may well endanger the very collections we are meant to protect through a systematic neglect of collections' item-level needs.

\section{Attitudes and Language}

G\&M took a reductionist view when writing about preservation and conservation activities. Their articles reveal that they view preservation as little more than climate control, folder replacement, and the "micro-conservation"12 task of paper clip removal. They emphasized this in declaring that we need to "make backlogs more embarrassing to the profession than failure to remove paper clips." 13 At times, their negative attitudes toward preservation make it seem as though they blame the removal of paper clips, staples, moldy materials, acidic folders, or insect infestations for the creation of backlogs. 
An oddly contentious relationship between access and preservation sometimes exists in the archival community. Some seem to believe preservation is antithetical to access and use $\mathrm{e}^{14}$ while, in reality, preservation is essential to promoting long-term access to collections. G\&M unfortunately joined this false dichotomy when they lamented that preservation is often seen as equal to access and scorned other authors' statements that give equal value to preservation and access. ${ }^{15}$ Further diminishing the importance of preservation, they declared archivists must not "allow preservation anxieties to trump user access and higher managerial values."16

Trivializing preservation activities, they wrote, "Much more often than not, we will (or should) find that we have larger, more urgent tasks in front of us-first and foremost converting our massive backlogs into usable resources for our patrons." ${ }^{17}$ In their rush to make backlogs available, an admirable and important goal, they undermined one of the stated core values of archives: preservation. ${ }^{18}$ Our collections must be accessible, but they must also be sustainable.

Throughout their articles, the general language Greene and Meissner employ is surprisingly negative. When it comes to preservation and conservation, they use phrases such as "essentially useless tasks," "self-imposed burden," "undermine more rational decisions," "tedious micro-conservation tasks," and "disjointed and haphazard dedication to certain rituals." 19 They discuss resources spent on preservation activities using terms like "squandered," "unconscionable," and "badly spent."20 Greene and Meissner use strongly negative and inflammatory terms when discussing preservation or conservation, often after dismissing other authors while presenting no counter-evidence.

\section{A Review of Selected Responses}

While reactions to both the concept of MPLP and the primary article on the subject have been somewhat mixed, most published responses focus on aspects of archives dealing with arrangement, description, or appraisal. Many of the articles inspired by "More Product, Less Process" are case studies measuring the success of various types of institutions in implementing MPLP for the processing of specific collections. One example is the Rudolf W. Becking Collection at Humboldt State University (HSU). Though many have viewed MPLP as a template for basic processing, Adrienne Harling wrote of "a nuanced understanding of MPLP as a decision-making framework." ${ }^{21}$ She described how HSU implemented MPLP for items of high value and added that "in some of the cases requiring unique decisions, it was not the intellectual content of the materials that warranted higher-level processing, but the logistics of their storage and the limitations of our storage facilities." ${ }^{22}$ Rather than stick to MPLP's decree that only the value of the collection should determine processing levels, Harling 
branched out to consider pertinent information about storage environments in making these decisions.

Only a few articles critique MPLP's stance on preservation and conservation actions. Robert Cox, in "Maximal Processing, or, Archivist on a Pale Horse," ${ }^{23}$ proposed a three-stage program for processing, beginning with a condition survey, continuing with minimal processing, and always having maximal processing as the end goal. He focused on what can be done rather than on the archives' limitations: "the equation should be reversed from the minimal model: archivists should seek to maximize both the physical and intellectual care of collections . . . within the real and practical limits of the resources at their disposal." ${ }^{24}$ Cox expressed concern about the long-term consequences of MPLP, writing that "small effects operating over a long time can have large consequences. . . . The additional costs imposed on appraisal, reference, retrieval, and preservation may individually be small, but when tabulated across the entire minimally processed corpus" 25 and extrapolated across the collections' lifetimes, these costs become much more significant.

Laura McCann wrote the first real critique of "More Product, Less Process" to use a preservation lens, focusing on G\&M's myopic view of preservation as "micro-conservation." She emphasized that "continued access requires preservation activities, particularly preventive conservation activities." ${ }^{26}$ While McCann recognized MPLP's push for climate control, she wrote that it does not go far enough. To properly care for collections, archives also need disaster and integrated pest management plans as well as policies for handling, storage, and use of materials. ${ }^{27}$

The extant literature sometimes touches briefly on the topic of preservation, but aside from McCann's contribution about preventive care, very few authors have taken it on. M\&G recognized this in their response to the many authors criticizing their original article on MPLP for other reasons when they wrote that "It would be one thing, for example, to challenge our premise that use is more important than preservation." ${ }^{8}$ This article addresses the assertion that use trumps preservation, the attitudes fueling the authors' antipathy toward the latter, and the importance of preservation within archives. The article also synthesizes previous commentary with additional discussion and offers suggestions for efficient preservation techniques.

\section{The Role of Preservation}

Several terms are used to describe care of collections. Preservation ${ }^{29}$ is generally used as the umbrella term comprising conservation, holdings maintenance, and preventive care-sometimes called preventive conservation. Defined quite simply: conservation activities work to counteract current damage (e.g., 
removing rusty staples or mending tears); preservation works to prevent the future occurrence of damage (e.g., replacing acidic folders or removing nonrusted staples); preventive care is the subset of preservation activities that operate at the institutional level (e.g., climate control or integrated pest management); and holdings maintenance is the subset of preservation and conservation activities that act at the collection level to ensure appropriate and nondamaging housing and may well require action at the item or folder levels. ${ }^{30}$

In 1956, Theodore Schellenberg proclaimed, "use is the end of all archival effort." ${ }^{31}$ While this may be true, it is only partially so. One would more correctly say that use is one end of archival effort. According to SAA's "Core Values of Archivists," an archivist's ethical concerns include access and use, accountability, advocacy, diversity, history and memory, preservation, professionalism, responsible custody, selection, service, and social responsibility. ${ }^{32}$ If we discard the core value of preservation, then we put the values of access and use, accountability, history and memory, responsible custody, and social responsibility at risk.

While G\&M do briefly recognize archivists' responsibility in regard to preservation, at the same time their articles read as distinctly antipreservation. They are at odds with their own words, describing archives as "a very practical profession that is first and foremost about managing things, specifically the ownership, preservation, and ... use of these evidential, documentary, and cultural assets" while also lamenting the "holdover conviction that archivists are custodians." 33 In their initial article on MPLP, G\&M championed mediocrity, oversimplifying the archivist's role, stating their "job is simply to represent the materials sufficient to affording acceptable access." ${ }^{34}$ A more complete look at the archival profession came from Mary Lynn Ritzenthaler when she wrote, "Preserving and providing access to social memory is at the core of archival values, and the failure to do so undermines the significance of archives." ${ }^{35}$ Both preservation and access play important fundamental roles in an archives and must be balanced to the needs of the collection and the institution.

McCann accurately asserted, "Condition can trump value or usage when the physical state of materials presents a risk to other objects or staff/users, such as items infested with mold or insects." ${ }^{36}$ This is also true for instances where the physical state of the enclosures jeopardizes the materials they contain or where the collection materials pose a risk to themselves, as is the case with highly acidic materials. We should not downplay the importance of preservation to the long-term viability of an archival collection. We preserve now to avoid having to conserve later. To ignore the condition of materials is to allow them to fall into disrepair and is in opposition to SAA's Code of Ethics. Ritzenthaler said it well: "Mismanagement of archival records that results in loss or damage falls within the realm of the archivist and top management, and 
in part can be attributed to institutional policies and programs that endanger archival materials through casual inattention, sloppy procedures, or persistent neglect of preservation needs." 37

\section{Analysis of the Greene and Meissner Survey}

A few authors have noted problems with the initial survey completed by G\&M. Carl Van Ness pointed to ambiguities and imprecision in the language used in the survey, noting that "Usually could mean anything from 50\% of the time to 99\%." 38 Van Ness indicated that never and always were the only two clear answers, leaving seldom, sometimes, and usually as undefined options. He also noted that the survey questions included multiple items, for example, the question about "paper clips also included staples" and the one on newsprint also included "carbons, thermal faxes, and thermal photocopies." ${ }^{39}$ The problem is that one might always or usually take a certain action with thermal faxes or paper clips but never or seldom with newsprint or staples.

While the language in some of G\&M's survey questions is unfortunately vague, at other times it is either too specific or misguided. The survey questions asked about photocopying at-risk items onto buffered paper, yet they did not ask about copying onto acid-neutral paper. ${ }^{40}$ While paper containing an alkaline reserve is recommended for preservation photocopies, ${ }^{41}$ a reasonable compromise for the purpose of cost savings would be to make these copies onto unbuffered, acid- and lignin-free paper. It is not inconceivable that some institutions might already choose this second option, thus leading them to mark never or seldom when answering the survey question. This would skew the results to show fewer institutions photocopying physically or chemically fragile documents. Quite baffling, however, is the survey question about deacidifying brittle paper. ${ }^{42}$ Very few respondents indicated that they deacidified brittle materials even on a rare basis, which is no surprise. While deacidification is a process that effectively neutralizes acids, it does not restore flexibility to paper and, thus, is a procedure best done much earlier in a document's life. Once brittle, a document will benefit very little from deacidification, and better options would be to reformat the document or to undertake a more intensive treatment.

Christopher J. Prom provided a thoughtful analysis of G\&M's survey, noting that regardless of how G\&M wanted to interpret their survey results or of the way they presented them, little correlation exists between the results and the practices they wish to end;33 moreover, "Any archivist attempting to eliminate his or her processing backlog by deciding to leave documents paper-clipped or stapled together in their original folders will be quickly disappointed." ${ }^{44} \mathrm{G \& M}$ pointed quite directly to preservation and conservation activities among the culprits causing archives to often have such large backlogs. ${ }^{45}$ Prom noted that 
while one might logically expect institutions reporting more intensive processing and preservation programs to also report lower processing efficiency, "one cannot safely say whether the processing/preservation practices and policies they excoriate (for example, removing paper clips and replacing folders) actually correlate to low processing rates. . . . it is never statistically proven." ${ }^{46} \mathrm{Far}$ from the survey results indicating a mandate to eliminate thorough processing and preservation practices, no correlation exists between these practices and reduced processing efficiency. ${ }^{47}$

The authors of "More Product, Less Process" presented the survey results in a manner that, while giving technically correct information, does not present a complete picture of the responses and may result in misinterpretation of the data by readers. They started with the "working hypothesis that processing projects squander scarce resources because archivists spend too much time on tasks that do not need doing, or at least don't need doing all the time," ${ }^{8}$ and then presented their survey results in such a way as to support this premise. While again introducing some ambiguity into the survey questions by not operationally defining what constitutes proper climate control, G\&M reported that "of the repositories that usually or always remove metal fasteners from twentieth-century collections, 33 report having 100\% of their stack areas properly controlled for temperature and humidity." ${ }^{49}$ This is a true statement, yet it is misleading, for it makes it appear as though the large majority of those who always or usually remove staples and paper clips have proper climate control. What they fail to mention, however, are the 30 other institutions that usually or always do these tasks and do not have $100 \%$ of their stack areas properly climate controlled. A clearer way to present this information would be as a percentage of the whole. The 33 that they tout represent just $52.4 \%$ of the total respondents. ${ }^{50}$ The authors then go on to write that "Similarly, of the repositories that usually or always refolder twentieth-century collections into 'archival' buffered folders, 37 have completely climate-controlled stacks." ${ }^{11}$ Again, this is partial information. In the appendix to G\&M's article, 85 institutions are listed as usually or always refoldering materials, meaning that of this group, only $43.5 \%$ report having completely climate-controlled stacks. ${ }^{52}$ G\&M argue against archivists refoldering collections and present their facts in a way that seems as though the large majority of the institutions usually or always refoldering have proper climate control when, in fact, $56.5 \%$ report not having $100 \%$ of their collection storage areas controlled.

\section{Preventive Care}

Preventive care strategies that contribute significantly to the long-term preservation of a collection include emergency preparedness, climate control, 
integrated pest management, and care and handling policies. The only method of preventive care that G\&M promoted as an appropriate step for archival institutions practicing MPLP is climate control; however, they failed to define good climate control. Without describing for either their survey group or their readership what constitutes good climate control, they encourage archivists to cease item-level preservation and conservation activities in favor of relying on a climate-controlled storage environment to adequately protect materials..$^{53}$ They are correct that climate control is an important first step in the preservation of materials entrusted to our care. Indeed, if institutions can only do one thing toward the preservation of their collections, they should ensure proper climate control. $^{54}$

Having good climate control is essential to the long-term preservation of collections, but it does not eliminate the need for any further preservation or conservation work. It is true that perfect climate control should create a stable environment for our collections; however, it does not make it a wise decision to knowingly or unwittingly introduce instabilities or weaknesses-metal fasteners, acidic storage materials, mold, or insects-into this controlled environment. To rely on climate control as the sole means of protecting materials is to believe that there will never be a power outage, leak, broken window, or malfunctioning HVAC unit, which would increase the risk of damage to all collections but especially to those that have been minimally processed. In a perfect world with perfect climate control, depending so heavily upon it might be fine; however, we do not operate in a perfect world, and many institutions do not have ideal storage conditions.

Relying solely on climate control for the preservation of collections may also prove risky as economic and environmental factors come into play. While touting climate control as the only appropriate preservation activity within the MPLP framework, M\&G admitted in their follow-up article that the revenue sources we need to offset the basic institutional costs of an archives are becoming increasingly uncertain and variable. ${ }^{55}$ Maintaining good storage conditions can be expensive, and building facilities managers are not always willing or able to lower the temperature even a few degrees for the sake of the collections. Likewise, as more institutions attempt to "go green," the high-energy consumption of the archives' climate control systems may well come under scrutiny. Mark Wolfe reiterated that MPLP pushes "the burden of preservation to the repository's climate control system" with the assumption that "traditional preservation treatments such as refoldering and reboxing with acid-free enclosures, removing metal fasteners and the like are not needed with modern climate control." ${ }^{56}$ He then warned that though repositories presently able to afford climate-control systems may see immediate benefit through the use of MPLP, "it may become a future stumbling block when institutions want to curb 
their carbon footprint through the adoption of less energy-intensive preservation environments." ${ }^{7}$ Thus it is risky to minimally process collections based on current ideal conditions with the assumption that the storage environment will never change.

Greene recommended focusing attention on the improvement of collections storage environments stating, "We must advocate for our repository with our resource allocators for better (not perfect) climate controls. Some of the time freed by minimal processing, for example, can be channeled into such advocacy." 58 First, why not advocate for perfect climate controls with the understanding that you will likely end up settling for something less-than-perfect but still better than you started with? Second, if you need to advocate for good climate control, you really cannot afford to do minimal processing so far as it extends to the preservation of the collection. M\&G claimed, "the more enlightened, and cost-effective, path to physical preservation comes through sturdy environmental controls and not through remedial document repair." 59 In reality, it is not a case of either climate control or item-level preservation efforts; rather, both should be considered as potentially necessary to the health of a collection.

\section{Refoldering}

In 2005, G\&M boldly claimed:

It may startle some archivists to learn that no studies have been done on the effect that standard manila folders have on collection material when stored in proper environmental conditions. In fact, no studies exist on the effect of buffered folders on collection material stored in proper conditions. We are spending lots of time and money in the hope that buffered folders can make a significant difference. ${ }^{60}$

Even if it were true that no formal studies had been conducted, at that time, on the efficacy of buffered folders or the damage caused by acidic ones, ${ }^{61}$ we have at hand a wealth of observations to this effect. One need look no further than a book that has once held newspaper clippings or pressed flowers within its leaves to see the effect of acid on paper. Nonetheless, G\&M dismissed even this observed evidence, stating quite falsely that "Although it has been ingrained in perhaps most of us that we ought to routinely replace file folders with acid neutral folders as we work our way through a collection, no really compelling preservation reason exists for doing so." ${ }^{62}$ Actually, numerous preservation reasons compel the replacement of folders. The primary reason, however, is that the goal of preservation is to prevent damage to the materials in our care. By storing collection materials in acidic folders, we contribute to the future decay of the documents. Whether or not the condition of materials improves through 
their storage in buffered folders, damage certainly comes through their storage in contact with acidic ones.

While recognizing the existing preservation literature, albeit in an overly dramatic manner:

the preservation sources we examined in our literature review nearly all contain at least the implicit notion that the inside of a file folder is a grisly and dangerous environment, one in which poor-quality paper is self-destructing at a rapid pace and taking down all its neighbors for good measure, ${ }^{63}$

G\&M nevertheless discounted-while making no effort to disprove-it. They simply presented the evidence provided by preservation experts and then discarded it as unimportant. They dismissed Ritzenthaler, Fredric Miller, Ross Harvey, and even the SAA's own preservation manuals, writing that "we can increase our processing efficiency by a huge factor if we adopt the more sensible policy of selectively replacing only damaged and seriously embrittled or overstuffed folders, avoiding altogether the practice of wholesale refoldering." ${ }^{64}$ A compromise can be made here. If an archivist were willing to test current folders with a $\mathrm{pH}$ pen, he or she could comfortably skip refoldering as long as, in addition to being physically sound, the existing folders did not read as acidic. This would save both time and cost over a program of comprehensive refoldering while still ensuring that damaging enclosures were not being included in the processed collections.

G\&M asked why archivists "spend so much money and time replacing every folder when in many instances the office folders the records arrive in are no more acidic than the paper inside them." ${ }^{65}$ They made a good point that not every folder needs to be replaced. Indeed, many folders might already be acidfree. As mentioned above, a quick check with a $\mathrm{pH}$ pen would allow the archivist to change only the acidic ones. The point, however, that the papers are likely also acidic, is moot. Acids will migrate from areas of higher concentrations to those of lower concentrations. ${ }^{66}$ Acidic folders, then, may cause harm if they transfer acids to the documents they are meant to protect as well as to hold. Acid-neutral folders will become acidic over time as they absorb some of the acids from the documents they hold; in this self-sacrifice they perform a service. Even better are buffered folders, which contain an alkaline reserve allowing them to absorb and neutralize the acids that migrate from the documents, thus extending the life of these materials.

In an apparent response to the flagrant dismissal of preservation standards in G\&M's 2005 article, Ritzenthaler wrote:

Some archivists and archival administrators have argued that it is a waste of money to use "acid free" folders and boxes to store records materials. However, the damage caused to records by acid-whatever its sources-is conclusive. A 
basic preservation principle is that any materials brought into contact with a collection must be non-damaging; suspect or untested materials should be kept away from valuable records. ${ }^{67}$

The above is true and should have a much greater impact on an archivist's decision to keep or replace damaging folders, since materials can gain acidity through contact with acidic storage materials. ${ }^{68}$

\section{Metal Fasteners}

Throughout "More Product, Less Process," G\&M made it painfully clear that they equate preservation mostly with removing paper clips and putting documents in acid-free folders. They were quick to discount the advice of preservation professionals and advocate "foregoing tedious micro-conservation tasks." 69 That they view certain tasks as tedious, however, does not make them unnecessary or inconsequential. G\&M indicated that most archivists use student or volunteer labor for carrying out mechanical tasks; this "presumes that we have nothing more important for volunteers or students to do than pry out staples or hand-write hundreds of folder labels." " It should not be forgotten that these "micro-conservation" tasks produce a significant benefit for the collections, particularly if, as is often the case, storage conditions are less than perfect.

Ritzenthaler gave multiple reasons for removing metal from our collections. Paper clips and staples can rust, stain, and serve as cutting edges against papers. Metal fasteners that are likely to cause damage, be it physical or mechanical, must be removed or replaced, while removing nondamaging ones can be deprioritized..$^{71}$ Ritzenthaler struck the correct chord here: paper clips and staples causing damage, either through their own inherent vices or due to the fragile nature of the documents they bind, should be removed, as well as any fastener that might cause damage in the future. Paper clips, staples, and other fasteners that will not likely cause damage need not be removed, provided the papers they hold are not inherently weak or brittle.

\section{Practitioners of Preservation Activities}

In deriding preservation tasks, $M \& G$ claimed, "The idea that performing essentially useless tasks is ok so long as they are performed by 'useless workers,' is specious from the start, and is ultimately insulting to the people assigned to perform that work." 72 Insulting, indeed. The authors put quotation marks around the term "useless workers" but did not cite any article as the source of this sentiment. Another article, published after M\&G's, also looked disparagingly upon volunteer, student, and part-time workers. In it, Carl Van Ness also 
denigrated preservation activities, writing that "considerable time and money are spent on mundane procedures that have little impact on the long-term preservation of the materials." He recommended eliminating these activities but then noted that this "scenario assumes that thousands of [full-time equivalents] currently employed in the removal of paper clips, newspaper clippings, and the like can be converted to something more useful."73

It is true that activities such as removing metal fasteners from a collection, replacing folders, sleeving photographs, photocopying, and other preservation tasks are often given to volunteer and student workers rather than to full-time staff. This is not, as Meissner, Greene, and Van Ness would have one believe, because neither the task nor the worker are important or useful. Rather, these tasks are assigned because they are often simple to explain, do not require much training or supervision, and, in fact, are not useless-ultimately improving the long-term viability of a collection. The fact that these tasks may prove time consuming while not especially challenging does not, in the least, detract from their importance or from the significant role those performing them play in our institutions.

\section{Levels of Processing}

In "More Product, Less Process," G\&M advocated doing all work at the same level. ${ }^{74}$ If a collection should be processed at the box level, then arrangement, description, and preservation should all take place at the box level. While it may make sense to tie the level of description to the level of arrangement, preservation is an entirely separate function and should take place not at a predetermined level but rather as needed. MPLP balks at this, with G\&M protesting, "Some authors and manuals suggest that it is appropriate and sensible to focus on the series level of arrangement and description, and then go on to insist that preservation measures be applied rigorously at the item level."75 Rather than let the condition of the materials determine the level of care, they advocated arranging, describing, and preserving "at a common level of detail-that is, if arrangement occurs only to the series level, so should description and preservation." 76 There is wisdom in saving time and resources by not fully acting on every document, but we must make educated decisions whether or not to act upon documents through item-level awareness of what preservation concerns exist within the collection.

If we persist in superficial processing of collections, not even looking into most folders, ${ }^{77}$ we may never discover serious preservation issues, or perhaps not until after damage has been done. Donna McCrea noted that she occasionally worries "that we may miss some significant preservation issue, such as an incidence of mold or the presence of nitrate film, but these same preservation 
issues exist when the collection remains unprocessed." 78 While it is true that mold, highly acidic materials, infestations, nitrate film, or other chemically unstable items may very well exist in backlogs, this cannot serve as justification for allowing them to remain indefinitely in our "processed" collections.

Nonetheless, a decision to perform item-level preservation in no way requires the archivist to take arrangement or description to a deeper level. Varying depths of activities need not be at odds with each other; rather, the level of activity should be determined by the needs of the records as well as the limitations of the storage facility.

\section{Conclusion}

More disconcerting than Greene and Meissner's cavalier attitude toward accepted preservation standards is that other archivists are making risky decisions based on their claims. While omitting details about the institution's temperature or relative humidity, one archivist wrote proudly of blindly following G\&M's recommendation to forego refoldering: "struck by their observation that no studies have been done to determine whether refoldering actually helps materials, in most cases, we stopped refoldering altogether."79 Once again, refoldering is less about improving materials and more about not contributing to their demise. But beyond that, a paucity of studies on a subject means nothing; it certainly should not negate years of observation. A procedure should not be discarded simply because someone claims it has not been studied. Rather, it would be more prudent to perform the study oneself and then determine, based on the results, if the procedure should stay or go.

In her case study on using MPLP for backlog management at the University of Montana at Missoula, McCrea described their "minimal processing-meaning no item-level preservation such as removing paperclips, sleeving photographs, or photocopying clippings; no refoldering, and typically no looking in folders." ${ }^{80}$ This method of processing seems rather risky. Not all basic preservation actions are required in all situations, but you must know what you have before you can choose to do nothing. And yet, this is exactly what MPLP advocates, referring to it as "a hard-nosed, pragmatic, forest-not-trees approach to processing." 81 G\&M wrote that one of them ${ }^{82}$ has "processed thousands of feet of railroad and other corporate records over the years-rarely poking around within folders" and then continued their analogy by claiming an archivist need not look at every tree to know the forest fairly well.$^{83}$ It sounds like the aforementioned archivist looked at very few trees at all! The forest, or archival collection, may look fine so long as we do not peer closely at any one tree. If we ignore the condition of the individual trees, we may not see until too late the disease or infestation that will destroy it and possibly the surrounding forest as well. 
As Laura McCann wrote, "Too often archivists and preservationists . . . invoke the supposed conflict between access and preservation yet under-emphasize how symbiotic the relationship really is." ${ }^{84}$ Archival collections need preservation as much as preservation needs collections. Without "the stuff," 85 as G\&M called it-be it physical or electronic-archives are useless and there is nothing to make accessible; therefore, it is incumbent upon us to preserve the items entrusted to us. McCann reiterated the balanced nature of the two fields in writing that "preservation and access are not dichotomous; accessioning and processing initiate preservation." ${ }^{86}$ She might well continue that preservation, in turn, facilitates long-term access. While preservation without allowing access may seem pointless, ${ }^{87}$ providing access while not ensuring preservation when possible is irresponsible.

MPLP has its merits and may well prove useful for the quick processing of archival collections. A few concessions must be made, however, to bring MPLP and preservation closer together. The two largest concerns pertain to the levels of processing and to "micro-conservation." MPLP's dictate that all processing on a collection (or portion thereof) must occur at a common level should not apply to preservation or conservation. These decisions should be based on the condition of the materials and the limitations of the storage environment. To facilitate this, at least a cursory item-level review is needed. Additionally, the "micro-conservation" tasks of refoldering, photocopying, paper clip removal, and so on need be neither automatic nor comprehensive. The removal of metal fasteners may be deprioritized if relative humidity levels are stable and sufficiently low. Photocopies may be made onto acid-/lignin-free unbuffered paper, and structurally sound folders need not be replaced as long as they are acid-free. Preservation is not the enemy of access; rather, it is its faithful companion.

\section{Notes}

1 Mark A. Greene and Dennis Meissner, "More Product, Less Process: Revamping Traditional Archival Processing,” The American Archivist 68 (Fall/Winter 2005): 208-63.

2 Greene and Meissner, "More Product, Less Process," 208-9.

3 Greene and Meissner, "More Product, Less Process," 212-13. Emphasis theirs.

4 Dennis Meissner and Mark A. Greene, "More Application while Less Appreciation: The Adopters and Antagonists of MPLP," Journal of Archival Organization 8, nos. 3-4 (2010): 174-226.

5 Mark A. Greene, “MPLP: It's Not Just for Processing Anymore,” The American Archivist 73 (Spring/ Summer 2010): 175-203.

6 Greene, “MPLP: It's Not Just for Processing Anymore,” 175.

7 Greene and Meissner, "More Product, Less Process," 240; Meissner and Greene, "More Application while Less Appreciation,” 176.

8 Greene and Meissner, "More Product, Less Process," 251.

9 Greene, "MPLP: It's Not Just for Processing Anymore,” 199.

${ }^{10}$ Greene, “MPLP: It's Not Just for Processing Anymore," 176. 
${ }^{11}$ Actually, according to Richard Pearce-Moses, A Glossary of Archives and Records Terminology (Chicago: The Society of American Archivists, 2005), 192, holdings maintenance is defined as "n. Preservation - Activities to stabilize materials for long-term storage by placing materials in appropriate housings and environments”; Greene, “MPLP: It’s Not Just for Processing Anymore,” 181.

${ }^{12}$ Meissner and Greene, "More Application while Less Appreciation,” 214.

${ }^{13}$ Greene and Meissner, "More Product, Less Process," 239. Emphasis theirs.

${ }^{14}$ Greene and Meissner, "More Product, Less Process," 221-22; Laura McCann, "Preservation as Obstacle or Opportunity? Rethinking the Preservation-Access Model in the Age of MPLP," Journal of Archival Organization 11, nos. 1-2 (2013): 37-38.

${ }^{15}$ Greene and Meissner, “More Product, Less Process,” 232.

${ }^{16}$ Meissner and Greene, "More Application while Less Appreciation,” 176.

17 Greene and Meissner, "More Product, Less Process,” 222.

${ }^{18}$ Society of American Archivists, "SAA Core Values Statement and Code of Ethics” (May 2011), http:// www2.archivists.org/statements/saa-core-values-statement-and-code-of-ethics.

${ }_{19}$ Meissner and Greene, "More Application while Less Appreciation," 215; Greene and Meissner, "More Product, Less Process," 234, 237; Meissner and Greene, "More Application while Less Appreciation,” 214; Greene and Meissner, "More Product, Less Process,” 230.

${ }^{20}$ Meissner and Greene, "More Application while Less Appreciation,” 253; Greene and Meissner, "More Product, Less Process," 221; Meissner and Greene, "More Application while Less Appreciation," 230.

${ }^{21}$ Adrienne R. S. Harling, "MPLP as Intentional, not Necessarily Minimal, Processing: The Rudolf W. Becking Collection at Humboldt State University,” The American Archivist 77 (Fall/Winter 2014): 489.

${ }^{22}$ Harling, "MPLP as Intentional, not Necessarily Minimal, Processing," 495.

${ }^{23}$ Robert S. Cox, "Maximal Processing, or, Archivist on a Pale Horse," Journal of Archival Organization 8, no. 2 (2010): 134-48.

${ }^{24}$ Cox, "Maximal Processing," 143.

${ }^{25}$ Cox, "Maximal Processing," 139.

${ }^{26}$ McCann, "Preservation as Obstacle or Opportunity?," 24.

${ }^{27}$ McCann, "Preservation as Obstacle or Opportunity?," 35.

${ }^{28}$ Meissner and Greene, "More Application while Less Appreciation,” 198.

${ }^{29}$ As this is the term G\&M use when referring to preservation and conservation activities together, this is what I will use as well.

${ }^{30}$ See entries for Preservation, Conservation, Preventive Care, and Holdings Maintenance in PearceMoses, A Glossary of Archival and Records Terminology (2005); Karen Garlick, "Holdings Maintenance: An Overview," The Book and Paper Group Annual 11 (1992), http://cool.conservation-us.org/coolaic/sg/ bpg/annual/v11/bp11-36.html.

31 Theodore Schellenberg, Modern Archives: Principles and Techniques (Chicago: University of Chicago Press, 1956), 224.

32 SAA, "SAA Core Values Statement and Code of Ethics."

${ }^{33}$ Meissner and Greene, "More Application while Less Appreciation,” 177; Greene, "MPLP: It's Not Just for Processing Anymore,” 177.

${ }^{34}$ Greene and Meissner, "More Product, Less Process," 247. Emphasis theirs.

${ }^{35}$ Matt Gorzalski, "Minimal Processing: Its Context and Influence in the Archival Community," Journal of Archival Organization 6, no. 3 (2008): 189.

${ }^{36}$ McCann, "Preservation as Obstacle or Opportunity?," 35.

${ }^{37}$ Mary Lynn Ritzenthaler, Preserving Archives and Manuscripts, 2nd ed., Archival Fundamentals Series II (Chicago: Society of American Archivists, 2010), 106.

${ }^{38}$ Carl Van Ness, “Much Ado about Paper Clips: 'More Product, Less Process' and the Modern Manuscript Repository,” The American Archivist 73 (Spring/Summer 2010): 134. Emphasis his.

${ }^{39}$ Van Ness, "Much Ado about Paper Clips," 134.

${ }^{40}$ Greene and Meissner, "More Product, Less Process," 259. 
${ }^{41}$ Ritzenthaler, Preserving Archives and Manuscripts, 59.

${ }^{42}$ Greene and Meissner, "More Product, Less Process,” 259.

${ }^{43}$ Christopher J. Prom, "Optimum Access? Processing in College and University Archives," The American Archivist 73 (Spring/Summer 2010): 146-174.

${ }^{44}$ Prom, “Optimum Access?, 158.

${ }^{45}$ Greene and Meissner, "More Product, Less Process,” 239, 251.

${ }^{46}$ Prom, “Optimum Access?,” 150.

47 Prom, "Optimum Access?," 158.

${ }^{48}$ Greene and Meissner, "More Product, Less Process," 209.

${ }^{49}$ Greene and Meissner, "More Product, Less Process," 231.

${ }^{50}$ Greene and Meissner, "More Product, Less Process," 259.

${ }^{51}$ Greene and Meissner, "More Product, Less Process," 231.

52 Greene and Meissner, "More Product, Less Process," 259.

${ }^{53}$ Greene and Meissner, "More Product, Less Process," 250.

${ }^{54}$ Ideal climate control will be the lowest sustainable temperature at which humidity can be maintained at a set point (desired RH levels vary depending on the materials to be stored) somewhere between $30 \%$ and $50 \%$. A temperature of $68^{\circ} \mathrm{F}$ is generally accepted for storage environments.

${ }^{55}$ Greene and Meissner, "More Product, Less Process," 250-51; Meissner and Greene, "More Application while Less Appreciation,” 209.

${ }^{56}$ Mark Wolfe, "Beyond 'Green Buildings': Exploring the Effects of Jevons' Paradox on the Sustainability of Archival Practices,” Archival Science 12, no. 1 (2012): 43;

57 Wolfe, “Beyond 'Green Buildings,'” 43.

${ }^{58}$ Greene, “MPLP: It’s Not Just for Processing Anymore,” 182.

${ }^{59}$ Meissner and Greene, "More Application while Less Appreciation,” 215.

${ }^{60}$ Greene and Meissner, "More Product, Less Process," 231. Emphasis theirs.

${ }^{61}$ See D. M. Burge, James M. Reilly, and Douglas W. Nishimura, "Effects of Enclosure Papers and Paperboards Containing Lignins on Photographic Image Stability," Journal of the American Institute for Conservation 41, no. 3 (2002): 279-90; George B Kelly Jr., "Practical Aspects of Deacidification," Bulletin of the American Institute for Conservation 13, no. 1 (1972): 16-28; Ellen McCrady, "Buffered Groundwood (Carbonate-Filled High-Yield Papers)," Alkaline Paper Advocate 9, no. 4 (1996), http:/ cool.conservation-us.org/byorg/abbey/ap/ap09/ap09-4/ap09-402.html.

62 Greene and Meissner, "More Product, Less Process," 251.

63 Greene and Meissner, "More Product, Less Process," 250.

${ }^{64}$ Greene and Meissner, "More Product, Less Process," 217-29; Greene and Meissner, "More Product, Less Process," 251.

65 Greene and Meissner, "More Product, Less Process," 235.

${ }^{66}$ Ritzenthaler, Preserving Archives and Manuscripts, 54.

${ }^{67}$ Ritzenthaler, Preserving Archives and Manuscripts, 186.

${ }^{68}$ Ritzenthaler, Preserving Archives and Manuscripts, 56.

${ }^{69}$ Meissner and Greene, “More Application while Less Appreciation,” 214.

${ }^{70}$ Meissner and Greene, "More Application while Less Appreciation,” 214.

${ }^{71}$ Ritzenthaler, Preserving Archives and Manuscripts, 248.

${ }^{72}$ Meissner and Greene, "More Application while Less Appreciation,” 215.

${ }^{73}$ Van Ness, "Much Ado about Paper Clips," 138; Meissner and Greene, "More Application while Less Appreciation,” 215.

${ }^{74}$ Greene and Meissner, "More Product, Less Process," 240.

${ }^{75}$ Greene and Meissner, "More Product, Less Process," 227.

${ }^{76}$ Greene and Meissner, "More Product, Less Process," 240.

${ }^{77}$ Greene and Meissner, "More Product, Less Process," 245. 
${ }^{78}$ Donna E. McCrea, “Getting More for Less: Testing a New Processing Model at the University of Montana,” The American Archivist 69, no. 2 (2006): 287.

${ }^{79}$ McCrea, “Getting More for Less," 287.

${ }^{80}$ McCrea, "Getting More for Less," 288.

${ }^{81}$ Greene and Meissner, "More Product, Less Process," 227.

82 They chose not to reveal if it was Greene or Meissner.

${ }^{83}$ Greene and Meissner, "More Product, Less Process," 245.

${ }^{84}$ McCann, "Preservation as Obstacle or Opportunity?," 37.

${ }^{85}$ Greene and Meissner, “More Product, Less Process," 234.

${ }^{86}$ McCann, "Preservation as Obstacle or Opportunity?," 37.

87 "Preservation without Access Is Pointless," Statement by the Committee for Film Preservation and Public Access before the National Film Preservation Board of the Library of Congress, February 12, 1993, 52-67, http://www.loc.gov/programs/static/national-film-preservation-board/documents/ fcmtefilmprespubaccess.pdf.

\section{ABOUT THE AUTHOR}

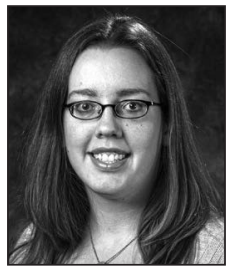

Jessica Phillips, head of preservation at the University of North Texas, works within the department of Special Collections. She received her MLIS from the University of Pittsburgh in 2006 and her BA in English from Marietta College in 2005. Phillips also is a member of TX-CERA (Texas Cultural Emergency Response Alliance) Steering Committee. 